\title{
Surgical Excision of Interdigital Pouch and Cyst in Sheep
}

\author{
Tarik Nabil Misk ${ }^{1}$ and Nabil Ahmed Misk ${ }^{2}$ \\ ${ }^{1}$ Department of surgery, radiology and Anesthesiology, Faculty of Veterinary Medicine, Sadat City \\ University, Sadat city, Menofia, Egypt \\ ${ }^{2}$ Department of surgery, radiology and Anesthesiology, Faculty of Veterinary Medicine, Assiut \\ University, Assiut, Egypt
}

Correspondence should be addressed to: Tarik Nabil Misk; misk0@yahoo.com

Received 3 August 2013; Accepted 18 August 2013; Published 18 October 2013

Academic Editor: Alexandre Coutinho Antonelli

Copyright $@ 2013$ Tarik Nabil Misk and Nabil Ahmed Misk. Distributed under Creative Commons CCBY 3.0

\begin{abstract}
The present study was carried out on a total number of six adult Saedi sheep and 16 thoracic and pelvic limbs of mature saedi sheep of both sexes collected from the slaughter house. In addition, two cases of interdigital cysts were reported in Rahmany sheep.

The results indicated that interdigital pouch is present in the four limbs of sheep of both sexes. The pouch is a tube like a pipe with long narrow neck and wide blind sac. Surgical excision of the pouch is easy and can be performed without any post-operative complications. For the first time, according to the available literatures, two cases of interdigital cysts were reported and subjected to treatment by excision of the cysts without any postoperative complications.
\end{abstract}

Keywords: Interdigital pouch; sheep; cyst; biflex canal.

\section{Introduction}

The skin of sheep has cutaneous pouches, which include; infraorbital pouch, inguinal pouch and interdigital pouch (IDP). The IDP (biflex canal) is a peculiar tubular invagination of the integument opens at the dorsal aspect of the interdigital cleft. It is a bent tube, extends downward and backward and then curved sharply upward between the distal ends of the first phalanges. On sagittal section, it resembles the shape of the pipe, composing of a narrow long neck and a blind sac(Frandson and spurgeon, 1992, Aslan et al., 2010).The subcutis forms a capsule around it. The skin of the pouch is thin, pale and bears fine colorless hairs, the follicles of which receive the secretion of several sebaceous glands(Frandson and spurgeon, 1992, Ashdown and Done, 2010, Nickel et al., 1981). The exact function of the IDP is unknown. Sheep showed an ability to distinguish between conspecifics by olfaction. They are able to discriminate between odors from pairs of secretion collected from Interdigital pouch of different animals (Baldwin and Meese, 1997).

Foot rot (FR), Interdigital Dermatitis (IDD), and contagious ovine digital dermatitis are

Cite this Article as: Tarik Nabil Misk and Nabil Ahmed Misk (2013), "Surgical Excision of Interdigital Pouch and Cyst in Sheep," International Journal of Veterinary Medicine: Research \& Reports, Vol. 2013 (2013), Article ID 187394, DOI: 10.5171/2013.187394 
almost the main causes of lameness in sheep (Paul, 2007, Winter, 2011, Winter, 2008). A question if IDP plays a role in infection causing lameness problems in sheep is not clear. In a retrospective study on 5549 sheep examined for lameness consequent to limb conditions in the arid zone of Nigeria, IDP inflammation was recorded in 167 cases (15.9\%) (Bokko et al., 2003). Moreover, the position of the pouch in the interdigital cleft makes it prone to injury(Sivachelvan et al., 1992).

The relation between IDP infection and FR will help in predicting best treatment and control methods. Different protocols are used for treatment of FR. In UK 34\% of farmers were interested in changing management of FR treatment (Wassink et al., 2010). Many authors didn't mention surgical excision of IDP as a method of control the infection with FR (Wassink et al., 2010, Green et al., 2007). On the other hand, some studies suggested surgical excision of IDP in young lambs specially in those areas of high incidence of infection causes lameness problems(Sivachelvan et al., 1992, Egwn et al., 1994).

Interdigital cysts were not recorded according to available literature. The obstruction of the duct may be due to consolidation of its secretion or accumulation of wool at its orifice. The present study deals with evaluation of the surgical excision of IDP in healthy sheep. In addition, two cases of interdigital cysts were reported.

\section{Materials and Methods}

Sixteen thoracic and pelvic limbs of adult Saedi sheep of both sexes (eight males and eight females) collected from a slaughter house were used for anatomical and radiological studies. The seat of pouch opening, the length and width, the shape and direction, the inner lying, and contents of the pouch were recorded. Contrast radiography of the pouch was made using Urographin $75 \%$ injected inside the pouch using a lacrimal needle. Lateral and dorsoventral exposures were performed.

Six mature sheep of both sexes (three males and three females) were used. The right thoracic and pelvic limbs were operated and the left limbs were left as a control. The operation was performed according to the following steps; the feet of the operated limb were prepared for aseptic surgery. Field block using Xylocaine HCL $0.5 \%$ (Depocaine®) was used for desensitization of the IDP area. The interdigital cleft was widened using gauze tape. One to two centimeters vertical elliptical skin incisions were performed including the orifice of the pouch. The orifice with the attached disc of skin was grasped and blunt dissection using a piece of gauze was continued around the neck of the pouch to the bottom until itis completely removed. Two small interrupted mattress stitches were used for skin coaptation using non-absorable suture materials. A protective bandage was applied for seven days. The skin stitches were removed ten days postoperatively. The results of operations and complications (if present) were recorded.

Two clinical cases of interdigital cysts were reported in adult female Rhamany sheep. Surgical excision was indicated under effect of local infiltration anesthesia using Xylocaine HCL $0.5 \%$ (Depocaine $\AA$ ) in a form of ring block at the level of the pastern joint. Postoperative assessment was performed.

\section{Results}

The interdigital pouch is present in the four limbs of sheep of both sexes. No differences were found between males and females as well as between thoracic and pelvic limbs. The opening of the IDP is present at the proximal part of the dorsal aspect of interdigital space at the level of the pastern joint. The opening is rounded in shape, seen grossly, and a metal probe can be introduced within it. The length of the pouch is $30 \pm 2 \mathrm{~mm}$. The diameter varies along its whole length. At the neck, it is around $10 \pm 2 \mathrm{~mm}$ while at the bulb, it is around $13 \pm 3 \mathrm{~mm}$. The shape of the IDP resembles the shape of a pipe. The narrow long neck is directed obliquely backward and downward then bent sharply on itself dorsoproximally to end as a blind sac. The pouch is interposed between the two digits 
just above the interdigital cleft. It is surrounded by connective tissue mixed with adipose tissue (Figure 1). The inner lining of the pouch, in a sagittal section, is formed of thin pale skin with fine tenuous hairs seen grossly (Figure 2). In some cases, a separate black tuft of hair was seen occluding the lumen. A sticky white sebaceous secretion was seen in several cases.

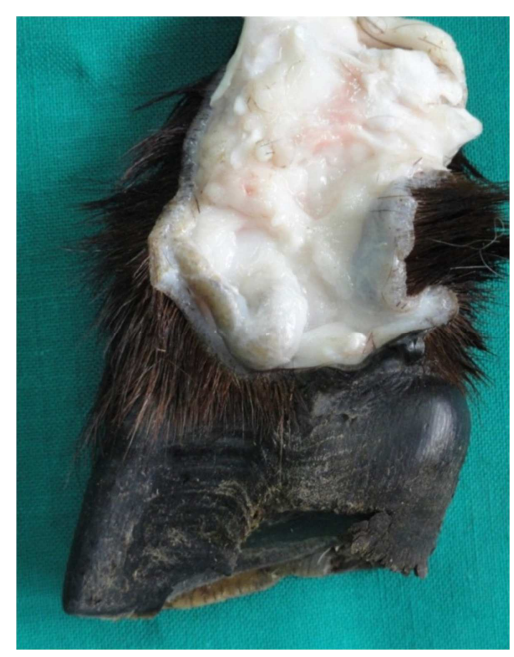

Figure 1: A Median Sagittal Incision at the Interdigital Cleft of the Claw. The IPD is PipeLike in Shape with a Narrow Long Neck and a Wide Blind Sac

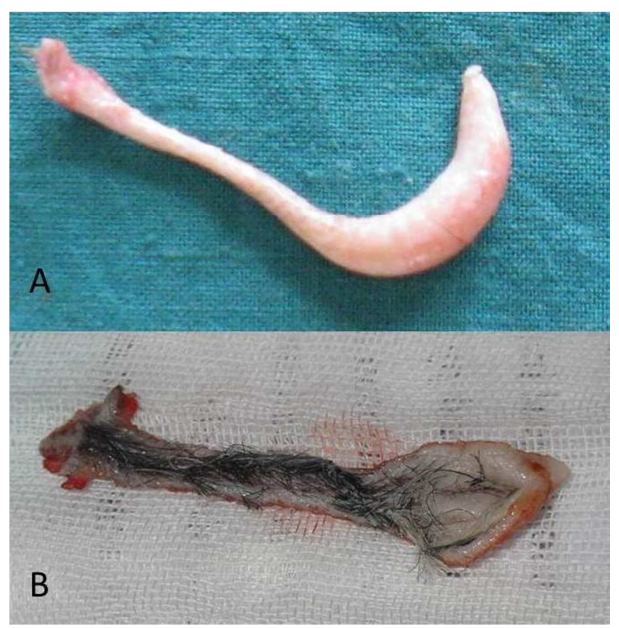

Figure 2: The IDP after Surgical Excision (A) and Longitudinal Section (B). The Inner Lining of IDP Consists of Pale Skin with Presence of a Tuft of Hair along its Whole Length

Lateral contrast radiography of the IDP revealed a presence of the opening of the pouch at the level of the proximal interphalangeal joints. The IDP extends downward and backward between the proximal halves of the middle phalanges until reach the level of the posterior surface of these phalanges then turns abruptly upward forming a wide blind sac which is situated just below the level of the proximal inter-phalangeal joints (Figure 3). The length of the IDP is $25 \pm 2 \mathrm{~mm}$, and the width is $6 \pm 2 \mathrm{~mm}$. Dorsopalmar/planter contrast radiography revealed the presence the pouch at the middle of interdigital space on the level of proximal halves of the middle phalanges. 


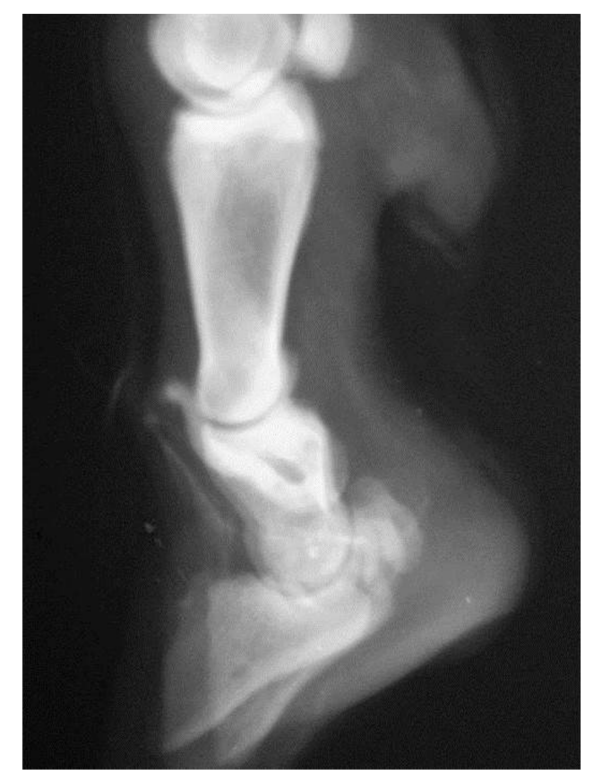

Figure 3: Lateral Contrast Radiography of the IDP of the Foot of a Sheep. The Opening of the Pouch is Present at the Level of the Proximal Inter-Phalangeal Joints. The IDP Extends downward and backward between the Proximal Halves of the Middle Phalanges until Reach the Level of the Posterior Surface then Turns Abruptly upward Forming a Wide Blind Sac

Experimental excision of the IDP was performed. The vertical elliptical skin incision was performed around the orifice of the pouch (Figure 4). Blunt dissection of IDP using a piece of gauze was sufficient to remove the pouch completely with no effort (Figure 5). No hemorrhage was detected. Skin coaptation using two interrupted horizontal mattress sutures were applied. First intention healing was occurred in all operated animals without any postoperative complications.

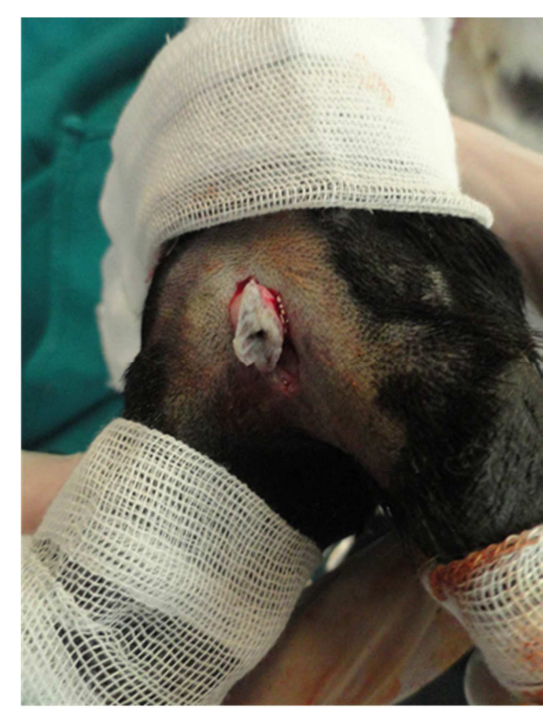

Figure 4: Operation for Excision of the IDP in a Sheep. An Elliptical Skin Incision is Performed around the Opening of the IDP 


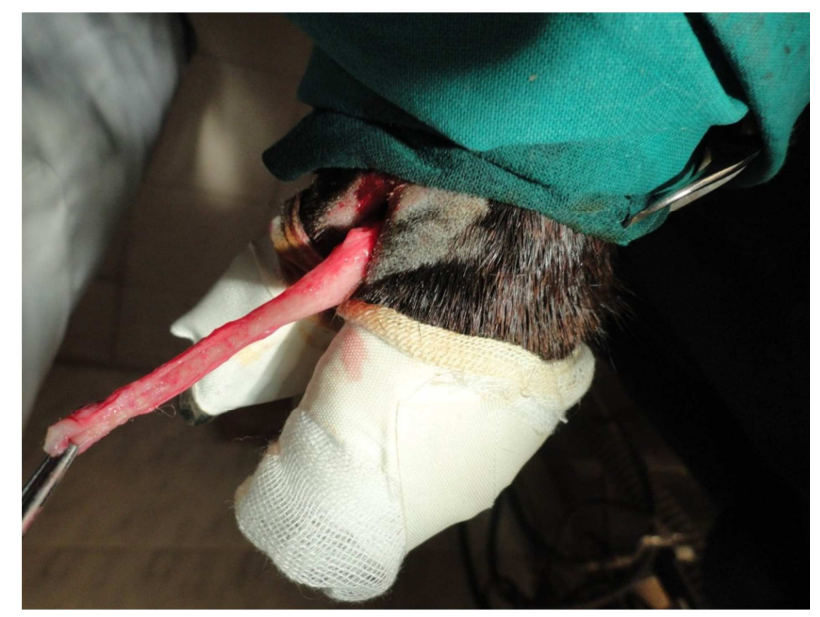

Figure 5: Operation for Excision of the IDP in a Sheep. A Blunt Dissection is Performed around the Pouch until Complete Extrusion

Two mature female Rahmany sheep (2 and 3.5 years old) were presented with a lemon's size doughy swelling at the interdigital space of the right thoracic limb in one animal and left pelvic limb in the second animal. Clinical examination of the animals revealed painless swelling with a slight degree of lameness. The cases were diagnosed as interdigital cysts and surgical excision was performed for treatment (Figure 6-8). Examination of the contents of the swellings revealed a presence of inspissated tenacious white-grayish materials. The wall of the cysts is lined by pale skin having some fine hairs. No postoperative complications were detected.

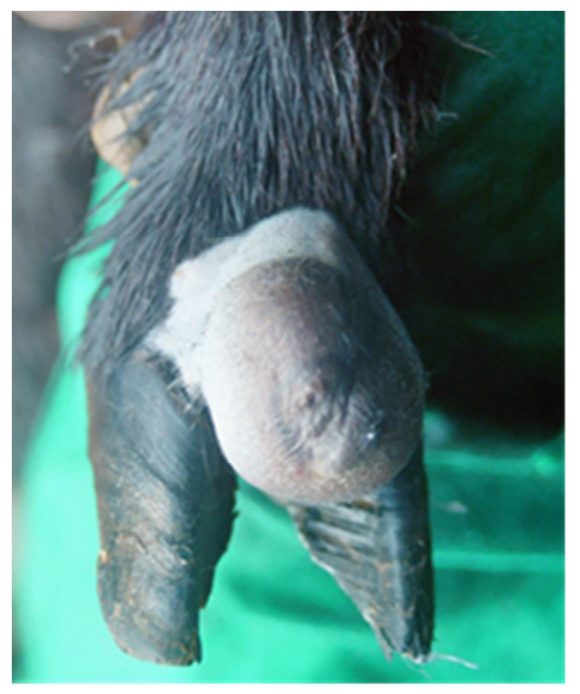

Figure 6: Interdigital Cyst at the Interdigital Cleft in a Sheep. A Lemon-Size Rounded Swelling is Present at the Interdigital Cleft 


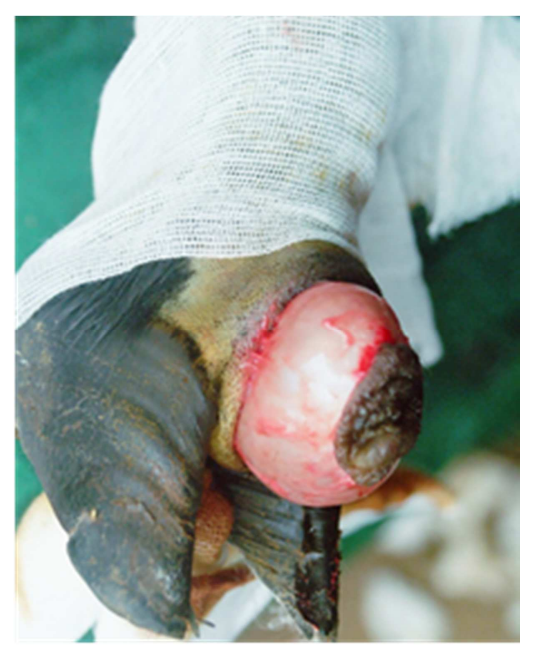

Figure 7: Interdigital Cyst at the Interdigital Cleft in a Sheep during Excision. The Cyst is Easily Dissected from the Surrounding Structures

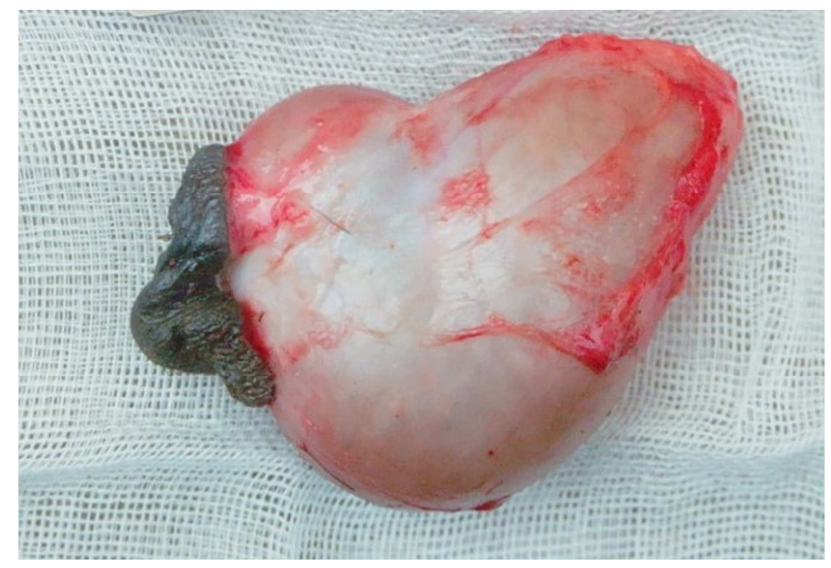

Figure 8: The Interdigital Cyst after Surgical Excision

\section{Discussion}

The current study agreed that the IDP is present in all feet of male and female sheep. It appears as a pipe possessing a narrow long neck and a blind wide sac interposed between the middle phalanges at the interdigital space (Aslan et al., 2010, Ganta et al., 2011, Ashdown and Done, 2010, Nickel et al., 1981).

Lateral Contrast radiography of IDP was satisfactory for exploration of the length, width, and direction of the pouch. DV contrast radiography justifies the presence of the pouch at the interdigital space and determines the seat of the pouch between digits at the level of the proximal halves of the second phalanges.
The results indicated that experimental surgical excision of the IDP was feasible and easy to be performed. The presence of elastic connective tissue surrounding the IDP facilitates its blunt dissection without any traumas to the neighboring structures (Bokko et al., 2003).

Anatomical position, shape and direction of the IDP may act as a reservoir of microorganisms and a continuous source of infection delaying the treatment of claw affections. Surgical excision of IDP may reduce time and cost of treatment with subsequent reduction of lameness in the affected limb. Although, surgical excision of IDP in healthy animals may differ from that with infection, which opens a question for further studies. The theory that infection 
and inflammation of the IDP are the main cause of foot-rot and other conditions affecting the feet of sheep is not justified (Egwn et al., 1994, Sivachelvan et al., 1992).

As the secretion of IDP serves as a "trail marker" for the animals, the treated animals may have problems in following their herds. However, the secretion of the infraorbital pouch functioning at territorial markers and that of inguinal pouch assisting the lambs to find udders of their mother could minimize this situation (Baldwin and Meese, 1997).

According to our available literatures, this study may be the first that reports the presence of interdigital cysts in sheep. The suspected etiology for formation of the cyst may be due to inflammation and infection or may be simply as a result of obstruction of the opening of the pouch by foreign bodies or tuft of detached hairs or even inspissated secretion. Surgical excision of the interdigital cyst may be indicated to relieve lameness and improve the aesthetical appearance of the limb.

In conclusion, the IDP is present in the four limbs of male and female sheep. The pouch is completely situated at the interdigital cleft. It is a pipe-like structure has a long narrow neck with a wide blind sac. Surgical anatomy and contrast radiography reveal the shape, position, direction, and relation of the pouch with the surrounding structures. Experimental surgical excision of the pouch was performed easily without any postoperative complications. Two cases of interdigital cysts were reported and the cysts were surgically removed.

\section{References}

Ashdown, R. R. \& Done, S. (2010). Colour Atlas of Veterinary Anatomy - Volume 1: The Ruminants, London, Mosby-Elsevier.

Aslan, K., Kurtul, I., Nazli, M. \& Ates, S. (2010). "Morphologic Features of the Interdigital Sinus of the Tuj Sheep," Kafkas Univ Vet Fak Derg 16, 623-626.

Baldwin, B. A. \& Meese, G. B. (1997). "The Ability of Sheep to Distinguish between
Conspecifics by Means of Olfaction," Physiology \& Behavior, 18, 803-808.

Bokko, B. P., Adamu, S. S. \& Mohammed, A. (2003). "Limb Conditions That Predispose Sheep to Lameness in the Arid Zone of Nigeria," Small Ruminant Research, 47, 165169.

Egwn, G. O., Adamu, S. S., Ameh, J. A., Onyeyili, P. A., Abana, S. P., Chaudhari, S. U. R. \& Rabo, J. S. (1994). "Retrospective, Clinicopathological and Microbiological Studies of Interdigital Pouch Lameness in an Arid Zone of Nigeria," Bulletin of Animal Health and Production in Africa, 42, 5-11.

Frandson, R. D. \& Spurgeon, T. L. (1992). Anatomy and Physiology of Farm Animals, Philadelphia, Lea and Febiger.

Ganta, C. V., Pentea, M. \& Pascu, K. (2011). 'The Topography of the Interdigital Sinus (Biflex Channel) In Sheep,' Lucrari Stiintifice - Universitatea De Stiinte Agricole a Banatului Timisoara, Medicina Veterinara.

Green, L. E., Wassink, G. J., GrogonoThomas, R., Moore, L. J. \& Medley, G. F. (2007). "Looking after the Individual to Reduce Disease in the Flock: A Binomial Mixed Effects Model Investigating the Impact of Individual Sheep Management of Footrot and Interdigital Dermatitis in a Prospective Longitudinal Study on One Farm," Preventive Veterinary Medicine, 78, 172-178.

Nickel, R., Schummer, A. \& Seiferle, E. (1981). 'The Circulatory System, the Skin, and the Cutaneous Organs of Domestic Mammals,' The Anatomy of the Domestic Animals. Berlin, Verlag, Paul Prey.

Paul, R. G. (2007). 'Chapter 15 - Infectious Diseases and other Conditions Affecting the Interdigital Space,' Bovine Laminitis and Lameness. Edinburgh, W.B. Saunders.

Sivachelvan, M. N., Yahaya, A. \& Chibuzo, G. A. (1992). "Developmental Changes in the Interdigital Pouch of Yankasa Sheep," Small Ruminant Research, 9, 303-312. 
Wassink, G. J., George, T. R. N., Kaler, J. \& Green, L. E. (2010). "Footrot and Interdigital Dermatitis in Sheep: Farmer Satisfaction with Current Management, Their Ideal Management and Sources Used to Adopt New Strategies," Preventive Veterinary Medicine, 96, 65-73.

Winter, A. C. (2008). "Lameness in Sheep," Small Ruminant Research, 76, 149-153.

Winter, A. C. (2011). "Treatment and Control of Hoof Disorders in Sheep and Goats," Veterinary Clinics of North America: Food Animal Practice, 27, 187-192. 